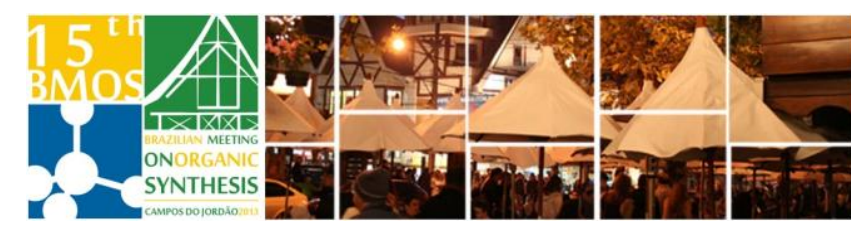

\title{
Studies on the Regio- and Enantioselective Heck Arylations of Acyclic Allylic Alcohols.
}

\author{
Caio C. Oliveira, Carlos Roque D. Correia
}

${ }^{\dagger}$ Instituto de Química, Universidade Estadual de Campinas, UNICAMP, C.P. 6154, CEP. 13083-970,

Campinas, São Paulo, Brazil

*caio.oliveira@iqm.unicamp.br

Keywords: Heck Reaction, Palladium, Allylic Alcohols

\section{INTRODUCTION}

Allylic alcohols is one of the most used substrates in the Heck reaction, not only because they are privileged building block in organic synthesis but also due the challenging control of the regioselectivity of the carbopalladation step. ${ }^{1,2}$ Although the styrenil adducts $\mathbf{3 a}$ and $\mathbf{4 a}$ are usually obtained as the major products, ${ }^{2}$ the aryl-carbonyl compounds such as $\mathbf{3 b}$ and $\mathbf{4 b}$ also represent interesting structural motifs for chemical synthesis if obtained in an enantioselective fashion (Scheme 1).

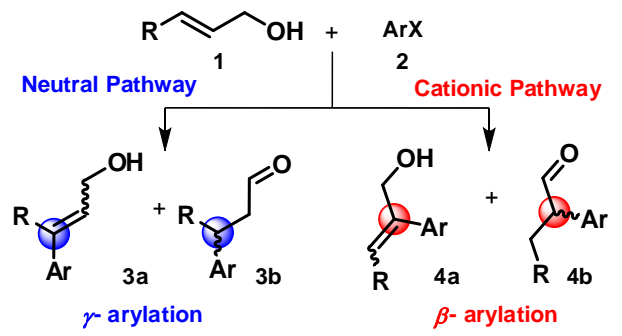

Scheme 1. Heck reactions with allylic alcohols.

Very recently, we reported the intermolecular desymmetrization of both cyclic ${ }^{3}$ and acyclic ${ }^{4}$ olefins by enantioselective Heck-Matsuda arylations (Scheme 2). As a further demonstration of the power of this method, we describe herein the more challenging arylation of non-symmetrical acyclic allylic alcohols and its applications in the synthesis of enantioenriched $\alpha$ - and $\beta$-aryl-aldehydes.

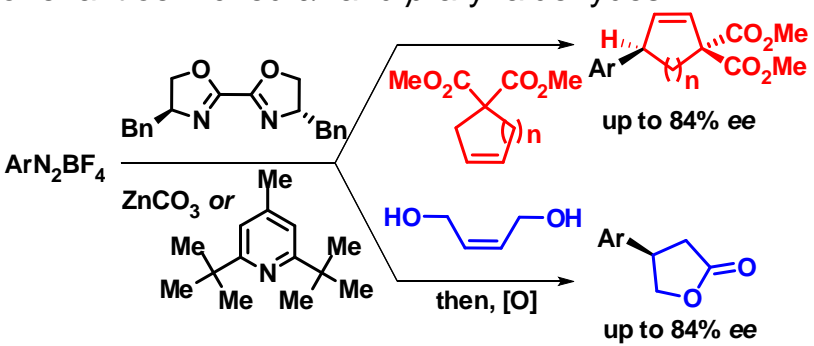

Scheme 2. Heck reactions of allylic alcohols.

\section{RESULTS AND DISCUSSION}

After optimization, we found that $E$-allylic alcohols provided the $\beta$-aryl-aldehydes as the major products in excellent ee values. On the other hand, the $Z$ allylic alcohols exhibited the opposite preference

during the carbopalladation, furnishing the $\alpha$-arylaldehydes (Scheme 3).

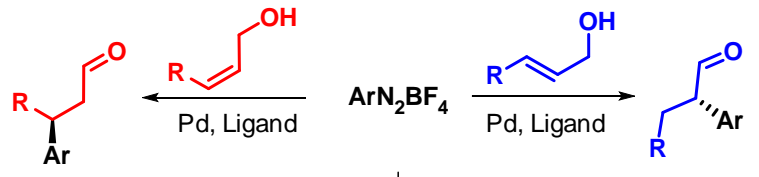

Chiral $\beta$-aryl-aldehydes

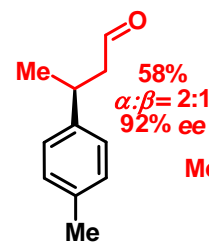

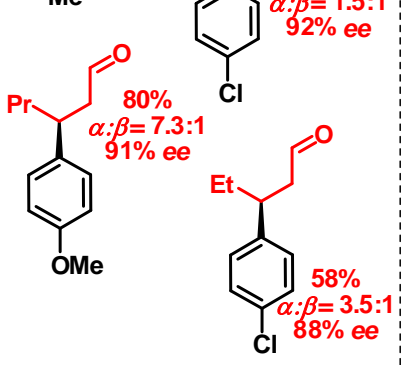

Scheme 3. Enantioselective Heck-Matsuda reaction of acyclic allylic alcohols.

\section{CONCLUSION}

In this preliminary work, we have shown that simple acyclic allylic alcohols can be arylated by the enantioselective Heck-Matsuda reaction with good yields and ee values. Although the regioselectivity for those reactions were modest, either $\alpha$ - or $\beta$-arylaldehydes could be synthesized according to the double bond configuration present in the substrate.

\section{ACKNOWLEDGEMENTS}

FAPESP, CNPq and Capes for financial support.

\section{REFERENCES}

${ }^{1}$ Lumbroso, A.; Cooke, M. L.; Breit, B. Angew. Chem. Int. Ed. 2013, 52, 1890.

${ }^{2}$ Beletskaya, I. P.; Cheprakov, A. V. Chem. Rev. 2000, 100, 3009

${ }^{3}$ Correia, C. R. D.; Oliveira, C. C.; Salles Jr., A. G.; dos Santos, E. A. F. Tetrahedron Lett. 2012, 53, 3325-3328.

${ }^{4}$ Oliveira, C. C.; Angnes, R. A.; Correia, C. R. D. J. Org. Chem. 2013, 76 4373. 